\title{
All you can eat Buffets, obesity, mindfulness, and mindful eating: An exploratory investigation
}

\author{
Zeeshan Ali ${ }^{1, x}$, Kai Wong ${ }^{1, x}$, Helen Egan ${ }^{1}$, Amy Cook $^{1}$ and Michael Mantzios ${ }^{1 *}$ \\ ${ }^{1}$ Department of Psychology, Birmingham City University, United Kingdom \\ xoined first authorship
}

\begin{abstract}
Obesity has been mostly explained through the change in our everyday environments and the increased availability of foods. All-You-Can-Eat-Buffets (AYCEB) is a typical example of the developing 'obesogenic' environment, but there is a paucity of research, which fails to explore both internal and external contributing aspects to eating behaviour. In two studies, the frequency of visits at AYCEB is investigated against the Body Mass Index (BMI), psychological traits (i.e., mindfulness and selfcompassion, $n=210$ ) and eating behaviors (i.e., mindful eating, $n=183$ ) which have been found to assist weight regulation. Results indicated that frequency of visits and BMI are unrelated. Significant relationships were found only with two subscales, where buffet visits negatively correlated with awareness within mindful eating, while a positive correlation was found between buffet visits and self-kindness. While results fit within the limited literature available, the generic future applicability of mindfulness-based constructs and interventions in eating behaviours is discussed.
\end{abstract}

\section{Introduction}

Eating in All-You-Can-Eat-Buffets (AYCEB) constitutes a 'different from usual' eating experience, which involves eating away from home, being exposed to larger portion sizes, and being in a food surplus environment; all of which form part of a greater westernization and economic development [1] that has led to an obesogenic environment. In other words, a higher frequency of visits to such restaurants may increase the chance of gaining weight. Individual elements such as personality traits and eating behaviours are clearly implicated in both successful and unsuccessful self-regulation, and these are more pertinent to the individual rather than the environment. The association between the obesogenic environment and human characteristics/behaviour are at the forefront of finding the causes and solutions of obesity, and are simultaneously explored in the present research, with an overarching aim of exploring relevant questions regarding AYCEB and providing future directives on healthy eating policies and interventions. Research investigating the impact of AYCEB on energy storage (i.e., weight gain) has been scarce. In fact, Temple and Nowrouzi [2] suggested that "research studies are needed that investigate whether buffets do indeed contribute to the excessive food intake and thence obesity" (p. 1), but outputs in the topic area remain limited. While some research has looked into the impact of economic decision making within restaurants [3], and observational studies have explored the amount eaten within such contemporary eateries [4], the association between visiting such restaurants and obesity is unknown. Specifically, whether the frequency of visiting AYCEB relates to an increased Body Mass Index (BMI), or higher BMI indicates a higher frequency of eating out at AYCEB is a question that has not been addressed. Within the literature, the role of personality traits and eating behaviours, which may relate and/or predict visiting and eating at AYCEB is unreported. Some of the traits that have recently been suggested to contribute to weight loss and weight maintenance, self-regulation and tolerance, as well as better psychological and physiological health, are mindfulness and self-compassion; which are explored in the present research.
A widely-accepted definition of the practice of mindfulness is that it is an awareness that emerges through purposefully paying attention in the present moment, non-judgmentally [5]. The practice usually entails mindfulness meditation, which involves actively observing the present moment by attending to the breath, moment-to-moment, and accepting all experiences (such as feelings and thoughts) without adding any meaning to them. This assists people who observe the constant flow of information to systematically develop an ability of acceptance (instead of judgment), and move on to more multi-layered indirect benefits, such as compassion, self-compassion and equanimity, which are parts of mindfulness practice [6,7]. A negative relationship was found between mindfulness and BMI in a recent population study with French adults $(\mathrm{N}=63.628)$ [8]. Furthermore, people who eat more mindfully, or participate in mindfulness meditation programmes have been found to improve the way they eat and successfully eat less [9-14]. However, Mantzios and Wilson [13] suggested that the combination of mindfulness and self-compassion might be more beneficial than mindfulness alone, and this was subsequently evidenced in other studies [15].

Neff $[16,17]$ described self-compassion as a kinder approach toward oneself, with a mindful awareness and understanding that one's experiences are part of what all people go through during personally challenging times [16,17]. Self-compassion consists of three main elements: self-kindness, common humanity, and mindfulness. These components combined, create the construct of self-compassion [17].

Correspondence to: Michael Mantzios, Birmingham City University, Department of Psychology, Faculty of Business, Law and Social Sciences, Birmingham, B4 7BD, UK; E-mail: michael.mantzios@bcu.ac.uk

Key words: mindfulness, mindful eating, self-compassion, obesity, all-you-can-eatbuffets

Received: April 22, 2017; Accepted: May 22, 2017; Published: May 25, 2017 
Self-compassion alone is underexplored in the context of weight regulation, however recent evidence suggests that it is self-compassion that explains the documented benefits of mindfulness and assisted weight regulation in recent psychological interventions for weight loss [18]. One of the issues for people when following a restricted diet, is that there are occasions when they 'break the diet', that is, consume 'forbidden' foods, or consume more food than is allowed. This break in the diet often triggers a prolonged increase in calorie-intake that hinders weight loss or regulation [19]. In an experimental study with restrictive eaters, Adams and Leary [20] used a short self-compassionate intervention with people who had broken their diet and found that this prolonged increase in food intake did not occur. Furthermore, recent research indicates that self-compassion plays a significant role across many aspects of weight regulation, in maintaining weight [18], in weight loss [15], and with different mindful practices (i.e., diaries instead of meditation) [13]. Other research suggests that selfcompassion may also provide positive outcomes in disordered eating. In a study including women with and without an eating disorder, results showed that participants benefited from self-compassion by breaking the negative cycle of shame, body image dissatisfaction and the drive for thinness [21]; all elements that are also evident and detrimental in dieting and overweight populations [22-24]. Overall, mindfulness and self-compassion appear to complement each other in ways that translate into better outcomes for both mental and physiological health. Specifically, research indicates that self-compassion explains the effectiveness of mindfulness practice, where people who scored higher in self-compassion experience more benefits from training in mindfulness than those who scored lower in self-compassion [25]. Other research suggested that self-compassion partially mediated the association between mindfulness and well-being [26], as well as mindfulness practice and stress [27], while well-being and stress are key determinants in eating and obesity $[28,29]$. Finally, recent research suggested that self-compassion (compared to mindfulness) was a more significant predictor of quality of life and psychological symptom severity in anxiety and depression [30], while again, there appears to be a clear association with anxiety and depression and obesity [31]. Therefore, the indirect benefits of both mindfulness and selfcompassion for weight regulation may be factors that can negatively relate and predict the frequency in which someone visits AYCEB.

The combination between mindfulness and eating has created a new drive for researchers who are specifically interested in investigating eating, and how well it conforms to the principles of mindfulness: namely, mindful eating. Mantzios and Wilson [18] suggested in a recent review that investigations need to be more explicit and specific to eating. Mindful eating is the application of mindfulness fundamentals on food-related experiences; that is, purposeful attention to the present moment with a non-judgmental or accepting attitude. Mindful eating has been related to healthier eating [32], and has been suggested to drop glucose levels and assist weight loss through mindfulness-based interventions [33]. Whether or not mindful eating relates to frequency of visits to AYCEB has not yet been explored.

Given the findings to date that suggest that mindfulness, selfcompassion, and mindful eating lead to healthier decision making in health contexts [34], we would expect this to translate into to fewer visits to AYCEB. In two studies, we firstly investigated the relationship of weekly, monthly, and yearly visits at AYCEB with BMI, mindfulness, and self-compassion. In a second study, it was considered important to additionally explore the relationship of weekly, monthly, and yearly visits at AYCEB with BMI again, but more specifically with mindful eating rather than generic mindfulness levels.

\section{Study 1}

In this study, we investigated the relationship of weekly, monthly, and yearly visits at AYCEB with BMI, mindfulness, and selfcompassion.

\section{Methods}

Participants: Two-hundred and ten students were recruited through an online invitation to take part in a study investigating eating behaviors. Participants $\left(\mathrm{M}_{\text {age }}=22.9, \mathrm{SD}=5.8 ; \mathrm{M}_{\mathrm{BMI}}=24.3, \mathrm{SD}=6.2\right.$; 127 females) were recruited on a voluntary basis and did not participate for any course credits or financial reward.

\section{Materials}

Participant information form: Participants' age, gender, ethnicity, socio-economic status, smoking status and frequency, usual price of AYCEB meal as well as weekly, monthly, and yearly visits, and finally height and weight were recorded. Questions regarding medication, health status, and eating disorders were also asked to serve for exclusion purposes.

Self-Compassion Scale (SCS): The scale calculates the qualities of the self-compassion construct. Responses are ranging from 1 (almost never) to 5 (almost always). Sample items are "When I'm feeling down I tend to obsess and fixate on everything that's wrong" (i.e., over-identification) and "I try to be understanding and patient toward aspects of my personality I don't like" (i.e., self-kindness). It is a 26-item scale (with overall scores ranging from 26 to 130) and it is composed of six subscales: self-kindness ( $\alpha=.77$ ), self-judgment ( $\alpha=.80)$, common humanity $(\alpha=.75)$, isolation $(\alpha=.80)$, mindfulness $(\alpha=.72)$ and overidentification $(\alpha=.78)$. The present study produced an alpha of .90 for the overall score and the alphas for the subscales are represented within the parentheses in the previous sentence.

Five Facet Mindfulness Questionnaire - Short Form (FFMQSF): [35] The FFMQ-SF is a 24-item questionnaire measuring five main characteristics of mindfulness. All items are scored on a 5-point Likert-type scale ranging from 1 (never or rarely true) to 5 (very often or always true). Sample items are "I watch my feelings without getting carried away by them" and "I find it difficult to stay focused on what's happening in the present moment", and higher scores indicate higher levels of mindfulness. The questionnaire is based on the original 39item version (FFMQ) [36], and the five measured facets are: observing ( $\alpha=.76)$, describing $(\alpha=.73)$, acting with awareness $(\alpha=.81)$, non-judging $(\alpha=.70)$ and non-reactivity $(\alpha=.74)$. The present study produced an alpha of .78 for the overall score.

\section{Procedure and design}

Potential participants responded to an advertisement of various online invitations at a University in the midlands of the United Kingdom. Participants were able to click on a link, which directed them to a participant information form, a consent form, and followed with the two questionnaires and the demographic information page. At the end of the study participants were directed to a debriefing form, which allowed them to learn more around the current investigation, and gave the opportunity to participants to record an arbitrary number to withdraw at a later stage and retain the anonymity of participation. Ethical approval was granted by the Ethical Committee based within the University and was scrutinized to strictly adhere to ethical guidelines set by the British Psychological Society. Data was analyzed by utilizing 
cross-sectional methods such as correlations and partial correlations to control for age, smoking frequency, etc., and via splitting files to explore differences between sex and weight groups.

\section{Results and discussion}

The descriptive statistics, including inter-correlations between the variables and subscales are presented in Table 1. Results show that AYCEB monthly visits positively correlate with BMI, while AYCEB weekly visits positively correlate with self-kindness. The results did not deviate when we controlled for smoking, age, or compared male to female correlation, and the positive correlation between self-kindness and AYCEB weekly visits did not agree with previous literature. Note that controlling for sex, age, smoking and socioeconomic status did not produce any significantly different results. (Table 1)

\section{Study 2}

In this study, we investigated the relationship of weekly, monthly, and yearly visits at AYCEB with BMI and mindful eating.

\section{Methods}

Participants: One-hundred and eighty-three students were recruited through an online invitation to take part in a study investigating eating behaviors. Participants $\left(\mathrm{M}_{\text {age }}=22.3, \mathrm{SD}=5.1 ; \mathrm{M}_{\mathrm{BMI}}\right.$ $=23.5, \mathrm{SD}=7.9 ; 121$ females) were recruited on a voluntary basis and did not participate for any course credits or financial reward.

\section{Materials}

Participant information form: Participants' age, gender, ethnicity, socio-economic status, smoking status and frequency, usual price of AYCEB meal as well as weekly, monthly, and yearly visits, and finally height and weight were recorded. Questions regarding medication, health status, and eating disorders were also asked to serve for exclusion purposes.

Mindfulness Eating Scale (MES) [45]. The MES is a 28-item scale, with a Likert scale ranging from 1 (Never) to 4 (Usually). Higher scores represent higher mindful eating. Sample items are "When I feel anxious, I find myself eating" and "I stay aware of my food whilst I'm eating". Five Subscales were indicated by the developers of the scale following a factorial analysis: Acceptance $(\alpha=.84)$, Awareness $(\alpha=.72)$, Non-Reactivity ( $\alpha=.70)$, Routine $(\alpha=.74)$, Distractibility $(\alpha=.69)$, and Unstructured $(\alpha=.54)$. The present study produced an overall alpha of .81 for the total score.

\section{Procedure and design}

Potential participants responded to an advertisement of various online invitations at a University in the midlands of the United Kingdom. Participants had the ability to click on a link, which directed them to a participant information form, an informed consent, and followed with the two questionnaires and the demographic information page. At the end of the study participants were directed to a debriefing form, which allowed them to learn more around the current investigation, and gave the opportunity to participants to record an arbitrary number to withdraw at a later stage and retain the anonymity of participation. Ethical approval was granted by the Ethical Committee based within the University and was scrutinized to strictly adhere to ethical guidelines set by the British Psychological Society.

Data was analyzed by utilizing cross-sectional methods such as correlations and partial correlations to control for age, smoking frequency, etc., and via splitting files to explore differences between sex and weight groups.

\section{Results and discussion}

The descriptive statistics, including inter-correlations between the variables and subscales are presented in Table 2. Results did not indicate that AYCEB visits correlate with BMI, while AYCEB weekly visits negatively correlated with the awareness subscale. Notably, the results in regards to the BMI do not agree with the first study, indicating that there are individual differences that are not captured within our demographic questionnaires. Note that controlling for sex, age, smoking and socioeconomic status did not produce any significantly different results. (Table 2)

Table 1. Means, Standard Deviations, and Bivariate Correlations between AYCEB visits and BMI, mindfulness and self-compassion, as well as corresponding subscales.

\begin{tabular}{|c|c|c|c|c|c|c|c|c|c|c|c|c|c|c|c|c|c|c|}
\hline & 1 & 2 & 3 & 4 & 5 & 6 & 7 & 8 & 9 & 10 & 11 & 12 & 13 & 14 & 15 & 16 & M & SD \\
\hline (1) BW & & & & & & & & & & & & & & & & & 1,86 & 1,39 \\
\hline (2) $\mathrm{BM}$ & $.852^{* *}$ & & & & & & & & & & & & & & & & 3,15 & 3,55 \\
\hline (3) BY & $.402^{* *}$ & $.554^{* * *}$ & & & & & & & & & & & & & & & 10,40 & 22,73 \\
\hline (4) BMI & -.048 & -.054 & -.025 & & & & & & & & & & & & & & 24,29 & 6,21 \\
\hline (5) SCS & .070 & .098 & $.179^{*}$ & .084 & & & & & & & & & & & & & 80,18 & 16,34 \\
\hline (6) FFMQ & -.004 & .068 & .092 & -.008 & $.646^{* *}$ & & & & & & & & & & & & 73,84 & 10,24 \\
\hline (7) SK & $.183^{*}$ & $.168^{*}$ & .144 & .086 & $.651^{* * *}$ & $.386^{* *}$ & & & & & & & & & & & 15,23 & 3,94 \\
\hline (8) SJ & -.087 & -.022 & .042 & .065 & $.801^{* *}$ & $.562^{* *}$ & $.365^{* *}$ & & & & & & & & & & 14,55 & 4,44 \\
\hline (9) $\mathrm{CH}$ & .098 & .022 & -.019 & .102 & $.621^{* *}$ & $.203^{*}$ & $.536^{* *}$ & $.205^{* * *}$ & & & & & & & & & 13,36 & 3,53 \\
\hline (10) I & -.016 & .010 & -.029 & .073 & $.771^{* *}$ & $.536^{* *}$ & $.170^{*}$ & $.684^{* *}$ & $.210^{* * *}$ & & & & & & & & 11,89 & 3,97 \\
\hline (11) $\mathrm{M}$ & .111 & .096 & .015 & .048 & $.696^{* *}$ & $.464^{* *}$ & $.602^{* * *}$ & $.286^{* *}$ & $.593^{* *}$ & $.357^{* * *}$ & & & & & & & 13,29 & 3,21 \\
\hline (12) OI & -.004 & .043 & .018 & -.010 & $.763^{* *}$ & $.581^{* *}$ & $.174^{*}$ & $.716^{* * *}$ & $.196^{* *}$ & $.796^{* *}$ & $.327^{* *}$ & & & & & & 11,52 & 3,79 \\
\hline (13) NR & .140 & .051 & .116 & .019 & $.591^{* *}$ & $.566^{* *}$ & $.458^{* * *}$ & $.349^{* *}$ & $.404^{* * *}$ & $.304^{* *}$ & $.502^{* *}$ & $.411^{* * *}$ & & & & & 15,54 & 3,84 \\
\hline (14) $\mathrm{O}$ & -.042 & -.086 & -.106 & .055 & $.203^{* *}$ & $.307^{* *}$ & $.362^{* * *}$ & -.002 & $.380^{* *}$ & -.056 & $.426^{* *}$ & -.050 & $.253^{* *}$ & & & & 13,24 & 3,76 \\
\hline (15) AA & -.108 & -.001 & -.110 & -.093 & $.300^{* *}$ & $.640^{* *}$ & .058 & $.348^{* *}$ & -.077 & $.351^{* *}$ & $.152^{*}$ & $.386^{* *}$ & .035 & -.148 & & & 15,00 & 4,35 \\
\hline (16) D & .070 & .094 & .021 & -.015 & $.374^{* *}$ & $.648^{* *}$ & $.212^{* *}$ & $.318^{* * *}$ & .076 & $.301^{* * *}$ & $.262^{* *}$ & $.352^{* *}$ & $.282^{* * *}$ & .048 & $.281^{* *}$ & & 16,26 & 3,90 \\
\hline (17) NJ & -.102 & .038 & .022 & .033 & $.273^{* *}$ & $.505^{* *}$ & -.060 & $.408^{* * *}$ & -.141 & $.451^{* * *}$ & -.075 & $.400^{* *}$ & -.028 & $-.299^{* * *}$ & $.545^{* * *}$ & .146 & 13,64 & 3,39 \\
\hline
\end{tabular}

Note: $\mathrm{BW}=$ Buffet visits per Week, BM= Buffet visits per Month, BY= Buffet visits per Year, BMI= Body Mass Index, SCS= Self-Compassion Scale, FFMQ= Five-Facet Mindfulness Questionnaire, SK= Self-Kindness Subscale, SJ= Self-Judgment Subscale, CH= Common Humanity Subscale, I= Isolation Subscale, M=Mindfulness Subscale, OI= Over-Identification Subscale, NR= Non-Reaction Subscale, $\mathrm{O}=$ Observe Subscale, AA= Acting with Awareness Subscale, D=Describe Subscale, NJ= Non-Judgment Subscale.

**. Correlation is significant at the 0.01 level.

*. Correlation is significant at the 0.05 level. 
Table 2. Means, Standard Deviations, Bivariate Correlations between AYCEB visits and BMI, mindful eating, as well as corresponding subscales.

\begin{tabular}{|c|c|c|c|c|c|c|c|c|c|c|c|c|}
\hline & 1 & 2 & 3 & 4 & 5 & 6 & 7 & 8 & 9 & 10 & M & $\mathrm{SD}$ \\
\hline (1) BW & & & & & & & & & & & 1,69 & 1,35 \\
\hline (2) BM & $.484^{* * *}$ & & & & & & & & & & 1,86 & 1,78 \\
\hline (3) BY & $.299^{* * *}$ & $.815^{* * *}$ & & & & & & & & & 5,25 & 7,19 \\
\hline (4) BMI & .098 & -.051 & -.015 & & & & & & & & 23,49 & 7,86 \\
\hline (5) ME & .024 & -.054 & -.062 & .141 & & & & & & & 74,82 & 9,35 \\
\hline (6) $\mathrm{AC}$ & .037 & .095 & .065 & -.007 & .725 & & & & & & 15,85 & 4,76 \\
\hline (7) AW & $-.175^{*}$ & -.130 & -.017 & .091 & -.158 & -.247 & & & & & 13,71 & 2,43 \\
\hline (8) NR & .029 & -.073 & -.089 & .056 & .649 & .254 & -.238 & & & & 13,51 & 3,33 \\
\hline (9) $\mathrm{R}$ & .018 & -.090 & -.071 & .025 & .354 & .198 & -.226 & .064 & & & 11,97 & 2,85 \\
\hline (10) D & .077 & -.096 & -.133 & .098 & .687 & .342 & -.344 & .519 & .069 & & 10,79 & 2,52 \\
\hline (11) UE & .085 & .056 & -.028 & .134 & .608 & .256 & -.209 & .370 & -.026 & .578 & 8,77 & 2,42 \\
\hline
\end{tabular}

Note: $\mathrm{BW}=$ Buffet visits per Week, $\mathrm{BM}=$ Buffet visits per Month, $\mathrm{BY}=\mathrm{Buffet}$ visits per Year, $\mathrm{BMI}=$ Body Mass Index, ME $=\mathrm{Mindful}$ Eating Scale, $\mathrm{AC}=\mathrm{Acceptance}, \mathrm{AW}=\mathrm{Awareness}$ Subscale, NR= Non-Reactivity Subscale, $R=$ Routine Subscale, $D=$ Distractibility Subscale, UE=Unstructured Eating Subscale.

**. Correlation is significant at the 0.01 level.

*. Correlation is significant at the 0.05 level.

\section{General discussion}

Overall findings were not as significant as expected based on previous literature. In fact, findings between the two studies showed differences with regard to the BMI and frequency of visits at AYCEB. Also, findings regarding self-kindness appeared to contradict previous findings, although this research explored a more generic decision making issue of the obesogenic environment (i.e., AYCEB) compared to more direct eating behaviors or calorie consumption. Only the awareness subscale of the mindful eating scale verified the hypothesis of mindful eating not being positively correlated to AYCEB visits. Findings are discussed consecutively and in more detail next. The relationship between BMI and frequency of visits at AYCEB suffers from several limitations, which may account for the contradictory findings. The formula of deriving a BMI figure depends upon height and weight measurements that are imprecise in separating adipose tissue from lean mass and skeletal frame size [37]. Hence, it is a more vague measure of obesity than most researchers (including ourselves) are prepared to accept. Other ways of measurement may have been more consistent across both studies, and requires further exploration. Furthermore, visiting and eating at an AYCEB may not necessarily be as detrimental to one's heath as suspected, if self-regulatory and inhibitory responses are in place. Wider explorations considering health theories such as interpersonal conflict and/or goal conflict theories [38-41], selfdetermination theory [42], and a justification-based model [43], may add further knowledge to the association between AYCEB and obesity.

In regard to the positive relationship between self-kindness and visits at AYCEB, it may be that visiting AYCWB is regarded as 'treating' oneself. The role of such treats in terms of positive and negative health behaviours, particularly eating behaviours, is complex and poorly understood. Mantzios and Egan [44] suggested that the wide separation between psychological and physiological health within the notion of self-kindness, and in effect, of self-compassion is problematic when investigating health behaviors and decision making. Self-kindness has been considered thus far a positive method of alleviating psychological distress when investigating the affective/cognitive side of self-kindness. However, being kind to yourself does not necessarily mean that both psychological and physiological health are achieved. In practice, we note that people frequently prioritize psychological over physiological health and vice versa. More research is required, and Mantzios and Egan [44] suggested that an association between self-kindness and self-care is required to achieve the most favorable version of selfkindness that will represented an equilibrium between body and mind in contemporary health research.
Last, the negative relationship between aware eating and visits at AYCEB is consistent with previous research. For example, [14] in a recent review suggested that "mindful awareness brings the eater's focus back to what one is eating." (p. 142). Furthermore, the items reflecting mindful awareness within the scale are similar to questions used in a recent intervention that proved to be successful for weight loss [13]. Future research should explore these findings further with better physiological measurements, and more specific measurements of consumption. One limitation already mentioned is the calculation of the BMI, which goes along with the self-reporting of weight and height, which may often lack accuracy. Future research will be able to determine with more clarity how buffet visits relate to obesity by using more detailed and specific measurements. Furthermore, the analyses were cross-sectional and require further explorations through field studies and experimental research. Addressing those limitations may enhance our understanding of what the relative contribution of the growing numbers of AYCEB restaurant is to the obesity epidemic, and provide directions for individual and collective actions and legislation to slow the continued increase in obesity figures.

\section{Conclusion}

Whether or not AYCEB contribute to the obesity epidemic remains a question for future research as the results are mixed between the two studies. While aware eating appears to be a type of eating behaviour that does not relate to buffet eating, what seems to raise more questions is the impact of self-kindness. The refinement of the self-kindness scale to fit in with a 'holistic model of body and mind', or, a physiological and psychological self-care-dependent self-kindness may prove more informative in explaining health behaviors and may provide resources to people who are aiming to regulate their weight.

\section{References}

1. The Obesity Society (2015) Potential Contributors to Obesity Infographic.

2. Temple NJ, Nowrouzi B (2013) Buffets and obesity. Clin Nutr 32: 664-665. [Crossref]

3. Siniver E, Yaniv G (2012) All-You-Can-Eat Buffet: Entry Price, the Fat Tax and Meal Cessation. The BE Journal of Economic Analysis \& Policy 12: 1-19.

4. Wansink B, Payne CR (2008) Eating behavior and obesity at Chinese buffets. Obesity (Silver Spring) 16: 1957-1960. [Crossref]

5. Kabat-Zinn J (1990) Full catastrophe living: Using the wisdom of your body and mind to face stress, pain, and illness. New York: Delacourt

6. Kabat-Zinn J (2006) Coming to our senses: healing ourselves and the world through mindfulness. New York: Hyperion 
7. Grossman P, Van Dam NT (2011) Mindfulness, by any other name...: trials and tribulations of sati in western psychology and science. Contemporary Buddhism 12: 219-239.

8. Camilleri GM, Méjean C, Bellisle F, Hercberg S, \& Péneau S (2015) Association between Mindfulness and Weight Status in a General Population from the NutriNetSanté Study. PloS one 10: e0127447.

9. Alberts HJ, Mulkens S, Smeets M, Thewissen R (2010) Coping with food cravings. Investigating the potential of a mindfulness-based intervention. Appetite 55: 160-163. [Crossref]

10. Daubenmier J, Lin J, Blackburn E, Hecht FM, Kristeller J, et al. (2012) Changes in stress, eating, and metabolic factors are related to changes in telomerase activity in a randomized mindfulness intervention pilot study. Psychoneuroendocrinology 37: 917928. [Crossref]

11. Kristeller JL, Hallett CB (1999) An Exploratory Study of a Meditation-based Intervention for Binge Eating Disorder. J Health Psychol 4: 357-363. [Crossref]

12. Kristeller J, Wolever RQ, and Sheets V (2014) Mindfulness-based eating awareness training (MB-EAT) for binge eating: A randomized clinical trial. Mindfulness 5: 282297.

13. Mantzios M, Wilson JC (2014) Making concrete construals mindful: A novel approach of developing mindfulness and self-compassion to assist weight loss. Psychology \& Health 4: 422-441. [Crossref]

14. Mantzios M, Wilson JC (2015) Mindfulness, Eating Behaviours, and Obesity: A review and reflection on current findings. Current Obesity Reports 4: 141-146.

15. Mantzios M, Wilson JC (2015b) Exploring mindfulness and mindfulness with selfcompassion-centered interventions to assist weight loss: theoretical considerations and preliminary results of a randomized pilot study. Mindfulness 6: 824-835.

16. Neff KD (2003a) The development and validation of a scale to measure selfcompassion. Self and Identity 2: 223-250.

17. Neff KD (2003b) Self-compassion: An alternative conceptualization of a healthy attitude toward oneself. Self and Identity 2: 85-101.

18. Mantzios M, Wilson JC, Linnell M, Morris P (2015) The role of negative cognitions, intolerance of uncertainty, mindfulness, and self-compassion in weight regulation among male army recruits. Mindfulness 6: 545-552.

19. Herman CP, Mack D (1975) Restrained and unrestrained eating. J Pers 43: 647-660. [Crossref]

20. Adams CE, Leary MR (2007) Promoting self-compassionate attitudes toward eating among restrictive and guilty eaters. Journal of Social and Clinical Psychology 26: 1120-1144.

21. Ferreira C, Pinto-Gouveia J, Duarte C (2013) Self-compassion in the face of shame and body image dissatisfaction: Implications for eating disorders. Eat Behav 14: 207-210. [Crossref]

22. Chernyak Y, Lowe MR (2010) Motivations for dieting: Drive for Thinness is different from Drive for Objective Thinness. J Abnorm Psychol 119: 276-281. [Crossref]

23. Conradt M, Dierk JM, Schlumberger P, Rauh E, Hebebrand J, et al. (2008) Who copes well? Obesity-related coping and its associations with shame, guilt, and weight loss. $J$ Clin Psychol 64: 1129-1144. [Crossref]

24. Gavin AR, Simon GE, Ludman EJ (2010) The association between obesity, depression, and educational attainment in women: the mediating role of body image dissatisfaction. $J$ Psychosom Res 69: 573-581. [Crossref]

25. Birnie K, Speca M, Carlson LE (2010) Exploring self-compassion and empathy in the context of mindfulness-based stress reduction (MBSR). Stress and Health 26: 359-371.

26. Hollis-Walker L, and Colosimo K (2011) Mindfulness, self-compassion, and happiness in non-meditators: A theoretical and empirical examination. Personality and Individual Differences 50: 222-227.
27. Shapiro SL, Astin JA, Bishop SR, Cordova M (2005) Mindfulness-based stress reduction for health care professionals: results from a randomized trial. Int Jour Stress Management 12: 164-176.

28. Gall K, van Zutven K, Lindstrom J, Bentley C, Gratwick-Sarll K, et al. (2016) Obesity and emotional well-being in adolescents: Roles of body dissatisfaction, loss of control eating, and self-rated health. Obesity (Silver Spring) 24: 837-842. [Crossref]

29. Torres SJ, Nowson CA (2007) Relationship between stress, eating behavior, and obesity. Nutrition 23: 887-894. [Crossref]

30. Van Dam NT, Sheppard SC, Forsyth JP, Earleywine M (2011) Self-compassion is a better predictor than mindfulness of symptom severity and quality of life in mixed anxiety and depression. J Anxiety Disord 25: 123-130. [Crossref]

31. Goossens L, Braet C, Van Vlierberghe L, Mels S (2009) Loss of control over eating in overweight youngsters: the role of anxiety, depression and emotional eating. Eur Eat Disord Rev 17: 68-78. [Crossref]

32. Jordan CH, Wang W, Donatoni L, and Meier BP (2014) Mindful eating: Trait and state mindfulness predict healthier eating behavior. Personality and Individual Differences 68: 107-111.

33. Mason AE, Epel ES, Kristeller J, Moran PJ, Dallman M, et al. (2015) Effects of a mindfulness-based intervention on mindful eating, sweets consumption, and fasting glucose levels in obese adults: data from the SHINE randomized controlled trial. $J$ Behav Med 39: 201-213. [Crossref]

34. Black DS, Sussman S, Johnson CA, Milam J (2012) Psychometric assessment of the mindful attention awareness scale (MAAS) among Chinese adolescents. Assessment 19: 42-52. [Crossref]

35. Bohlmeijer E, ten Klooster PM, Fledderus M, Veehof MM, \& Baer R (2011) Psychometric properties of the Five Facet Mindfulness Questionnaire in depressed adults and development of a short form. Assessment 18: 308-320. [Crossref]

36. Baer RA, Smith GT, Hopkins J, Krietemeyer J, Toney L (2006) Using self-report assessment methods to explore facets of mindfulness. Assessment 13: 27-45. [Crossref]

37. Romero-Corral A, Montori VM, Somers VK, Korinek J, Thomas RJ, et al. (2006) Association of body weight with total mortality and with cardiovascular events in coronary artery disease: a systematic review of cohort studies. Lancet 368: 666-678. [Crossref]

38. Carver CS (2005) Impulse and constraint: Perspectives from personality psychology, convergence with theory in other areas, and potential for integration. Pers Soc Psychol $\operatorname{Rev}$ 9: 312-333. [Crossref]

39. Strack F, Deutsch R (2004) Reflective and impulsive determinants of social behavior Pers Soc Psychol Rev 8: 220-247. [Crossref]

40. Stroebe W, Mensink W, Aarts H, Schut H, Kruglanski AW (2008) Why dieters fail Testing the goal conflict model of eating. Journal of Experimental Social Psychology 44: 26-36.

41. Tangney JP, Baumeister RF, Boone AL (2004) High self-control predicts good adjustment, less pathology, better grades, and interpersonal success. J Pers 72: 271 324. [Crossref]

42. Deci EL, Ryan RM (1985) The general causality orientations scale: Self-determination in personality. Journal of Research in Personality 19: 109-134.

43. De Witt Huberts JC, Evers C, De Ridder DT (2014) "Because I Am Worth It" A Theoretical Framework and Empirical Review of a Justification-Based Account of Self-Regulation Failure. Pers Soc Psychol Rev 18: 119-138. [Crossref]

44. Mantzios M, Egan HH (2017) On the Role of Self-compassion and Self-kindness in Weight Regulation and Health Behavior Change. Front Psychol 8: 229. [Crossref]

45. Hulbert-Williams L, Nicholls W, Joy J, and Hulbert-Williams N (2014) Initial validation of the mindful eating scale. Mindfulness 5: 719-729.

Copyright: (C)2017 Ali Z. This is an open-access article distributed under the terms of the Creative Commons Attribution License, which permits unrestricted use, distribution, and reproduction in any medium, provided the original author and source are credited. 